\title{
Clinical significance of catecholamine excretion levels in diagnosis and treatment of neuroblastoma
}

\author{
JANE V. BOND \\ From The Hospital for Sick Children and Institute of Child Health, London
}

\begin{abstract}
Bond, J. V. (1975). Archives of Disease in Childhood, 50, 691. Clinical significance of catecholamine excretion levels in diagnosis and treatment of neuroblastoma. The pattern of urinary excretion of vanillylmandelic acid (VMA) was studied in 50 children with neuroblastoma. There were 10 disease-free survivors, and 4 children who survive for 3 or more years with residual nonmetastatic disease. 36 children died with widespread metastatic disease.

The urinary VMA level was raised at diagnosis in 8 of the 10 disease-free survivors but rapidly returned to normal after treatment. In 3 out of 4 children with residual tumour, VMA remains persistently raised. In 28 of the 36 children who died VMA was raised at diagnosis and remained so throughout the course of their disease. In the majority of the children with metastatic disease the finding of a raised VMA revealed the nature of the primary tumour.

Measurement of urinary VMA is a simple diagnostic test which confirms the presence of neurblastoma and avoids the need for more complex investigations. The prompt return to normal levels in the disease-free survivors confirms the importance of serial VMA estimations in assessing response to treatment and ultimate prognosis. The other good prognostic features in the surviving patients were young age at diagnosis, primary tumour in the thorax, and histologically well-differentiated tumours which had not metastasized.
\end{abstract}

Increased urinary excretion of catecholamines or their metabolites occurs in association with ganglioneuroma, ganglioneuroblastoma, and neuroblastoma (Voorhess and Gardner, 1960). These neoplasms have a common origin from neural ectoderm and arise either from the adrenal gland or sympathetic nerve ganglia which normally secrete noradrenaline.

There is an abnormality of catecholamine excretion in almost every patient with neuroblastoma, the most constant being an increase in urinary levels of vanillymandelic acid (VMA) (Gitlow et al., 1970). The main metabolic pathyway for catecholamine synthesis and metabolism is shown below schematically. This may vary so that in a few patients there is a raised level of homovanillic acid (HVA) either in association with a raised VMA level or where the VMA excretion is normal (Liebner and Rosenthal, 1973).

The clinical value of VMA estimation in the early diagnosis of neuroblastoma and in monitoring

Received 23 January 1975. response to treatment and predicting ultimate survival has been assessed in a series of 50 children.

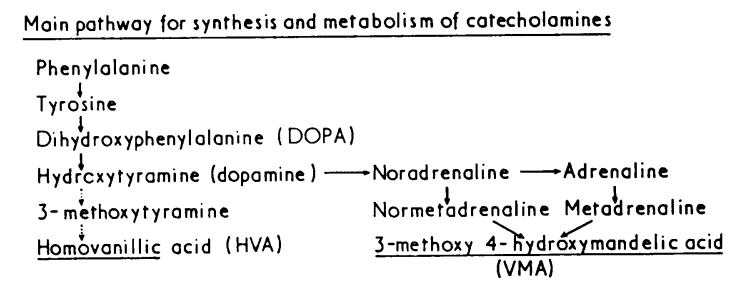

\section{Materials and methods}

Fifty children ( 33 boys and 17 girls) in whom a diagnosis of neuroblastoma was subsequently confirmed, were seen at the The Hospital for Sick Children between 1970 and 1973. 6 patients were referred directly ty their general practitioners and the remaining 44 were transferred from other hospitals, either for surgical management of an obvious thoracic, abdominal, or intraspinal tumour, or for advice on the investigation, diagnosis, and treatment of a difficult clinical problem. On admission VMA excretion level was measured in 
all patients in whom a diagnosis of neuroblastoma was suspected. A spot test (Labrosse, 1968) was used for initial screening and a further quantitative measurement of urinary VMA was then carried out on a 24-hour specimen of urine by the method of Pisano, Crout, and Abraham (1962). Further estimations were carried out after surgical resection of the primary tumour, when this had been possible, at the completion of radiotherapy, after any course of chemotherapy, and during the followup period. The upper limit of normal VMA excretion in healthy children at different ages is shown in Table I (Ruthven, 1963).

\section{TABLE I}

Upper limit of normal urinary VMA excretion levels (Ruthven, 1963)

\begin{tabular}{c|c}
\hline Age (yr) & VMA (mg/24 h) \\
\hline $0-\frac{1}{2}$ & 1 \\
$\frac{1}{2}-2$ & $2 \cdot 7$ \\
$2-3$ & $2 \cdot 9$ \\
$3-4$ & $3 \cdot 1$ \\
$4-5$ & $3 \cdot 3$ \\
$5-6$ & $3 \cdot 5$ \\
$6-7$ & $3 \cdot 7$ \\
$7-8$ & $3 \cdot 9$ \\
$8-9$ & $4 \cdot 1$ \\
$9-10$ & $4 \cdot 3$ \\
$10-11$ & $4 \cdot 5$ \\
$11-12$ & $4 \cdot 7$ \\
\hline
\end{tabular}

Whenever possible the diagnosis of neuroblastoma was confirmed by histological study of the primary tumour. However, in many children with metastatic neuroblastoma there was no obvious primary tumour and the diagnosis was made on the finding of multiple bone metastases together with a raised VMA, often associated with metastatic malignant cells in the bone marrow. In a few children biopsy of a bone lesion or lymph node $\overrightarrow{\overline{\vec{A}}}$ showed histological evidence of metastasis from an embryonal tumour, the nature of which was confirmed by the associated raised VMA level. The patients were staged clinically by the system of Evans et al. (1971b) shown in Table II.

\section{TABLE II}

Staging for children with neuroblastoma (Evans et al., $\stackrel{\vec{\circ}}{1971 b)}$

Stage I: Tumour confined to organ or structure of origin

Stage II: Tumour extending in continuity beyond the organ or structure of origin but not crossing the midline. Re-? gional lymph nodes on the homolateral side may be $O$ involved

Stage III: Tumours extending in continuity beyond the midline. Regional lymph modes may be involved bilaterally

Stage IV: Remote disease involving skeleton, organs, soft tissues, or distant lymph nodes

Stage IVs: Patients who would otherwise be stage I or II, but who have remote disease confined only to one or more of the following sites: liver, skin, or bone marrow (without $C$ radiographic evidence of bone metastases on complete $\mathbb{D}$ skeletal survey)

\section{Results}

Ten infants were under the age of one year at $\overrightarrow{0}$ diagnosis, 6 of whom survive over 2 years (60\%). The details of their age, sex, stage and site of tumour, initial VMA levels, treatment, and survival are shown in Table III. There was no delay in diagnosis and treatment in this group of patients since they all presented either with an obvious primary tumour, an enlarged liver, flaccid paralysis $\stackrel{\mathbb{Q}}{\varrho}$ due to compression of the spinal cord, or marked $\overline{\bar{O}}$ periorbital bruising and proptosis. VMA was

TABLE III

10 infants under age 1 year with neuroblastoma

\begin{tabular}{|c|c|c|c|c|c|}
\hline Case no. & Sex \& age $(m)$ & Stage & Site of tumour & Initial VMA (mg/24 h) & Treatment and survival \\
\hline \multicolumn{6}{|c|}{ Disease-free survivors } \\
\hline 1 & F 2 & III & $\begin{array}{l}\text { Thoracoabdominal intraspinal } \\
\text { neuroblastoma }\end{array}$ & $2 \cdot 6$ (became normal) & $\begin{array}{l}\text { Laminectomy; radiotherapy; } \\
\text { alive } 3 \mathrm{yr}\end{array}$ \\
\hline 2 & F 9 & III & $\begin{array}{l}\text { Thoracoabdominal intraspinal } \\
\text { neuroblastoma }\end{array}$ & $19 \cdot 6$ (became normal) & $\begin{array}{l}\text { Laminectomy; radiotherapy; } \\
\text { alive } 2 \text { yr }\end{array}$ \\
\hline 3 & F 7 & III & $\begin{array}{l}\text { Thoracic, supraclavicular } \\
\text { nodes }\end{array}$ & 48 (became normal) & Biopsy; radiotherapy; alive 1 \\
\hline 4 & M 2 & IVs & Adrenal; liver & 31.9 (became normal) & Adrenalectomy; radio- \\
\hline 5 & M 2 & IVs & ? Primary; liver, skin & 83.5 (became normal) & $\begin{array}{l}\text { Radiotherapy; chemo- } \\
\text { therapy; alive } 1 \text { yr }\end{array}$ \\
\hline \multicolumn{6}{|c|}{ Residual tumour } \\
\hline Nons & M 4 & IVs & Thoracoabdominal, skin & 22 (remains raised) & $\begin{array}{l}\text { Partial removal; chemo- } \\
\text { therapy; alive } 4 \mathrm{yr}\end{array}$ \\
\hline $\begin{array}{c}\text { Nonsurvivors } \\
7 \\
8\end{array}$ & $\begin{array}{l}\text { F } 4 \\
\text { F } 7\end{array}$ & $\begin{array}{l}\text { IVs } \\
\text { IV }\end{array}$ & $\begin{array}{l}\text { Adrenal; liver } \\
\text { ? Primary; orbit, liver, } \\
\text { marrow }\end{array}$ & $\begin{array}{l}4 \cdot 8 \\
30\end{array}$ & $\begin{array}{l}\text { Died on admission } \\
\text { Radiotherapy; chemo- } \\
\text { therapy; died } 1 \mathrm{~m}\end{array}$ \\
\hline $\begin{array}{r}9 \\
10\end{array}$ & $\begin{array}{l}\text { M } 6 \\
\text { M } 7\end{array}$ & $\begin{array}{l}\text { IV } \\
\text { IV }\end{array}$ & $\begin{array}{l}\text { Adrenal; orbit, marrow } \\
\text { Abdominal; liver, skin, } \\
\text { marrow }\end{array}$ & $\begin{array}{l}1 \cdot 7 \\
33 \cdot 9\end{array}$ & $\begin{array}{l}\text { Chemotherapy; died } 3 \mathrm{~m} \\
\text { Laparotomy; died post- } \\
\text { operatively }\end{array}$ \\
\hline
\end{tabular}


raised initially in the 5 disease-free survivors and returned to normal levels after treatment. One patient survives at 4 years with a persistently raised VMA and $x$-ray evidence of a residual left thoracoabdominal paravertebral mass, though the original skin lumps have all regressed. Three infants had widespread metastatic disease and died soon after admission. One patient with stage IVs disease died before effective treatment could be started, though the majority of infants with this pattern of metastatic disease require only minimal treatment to initiate regression (D'Angio, Evans, and Koop, 1971).

Forty children were over the age of one year at diagnosis and of these only 8 survive after 2 or more years (20\%). Details of survivors are given in Table IV. This group of 8 patients all presented either with neurological symptoms from spinal cord compression, Horner's syndrome, or an obvious abdominal or pelvic mass, and none had bone metastases. There was little delay in making the diagnosis, which was confirmed histologically at operation in all but one patient, and in 5 patients the primary tumour was shown to be a ganglioneuroblastoma. In the 3 disease-free survivors in whom VMA was raised initially, the level became normal after treatment and in the other 2 diseasefree survivors VMA was never raised.

Three children survive for 2 or more years with residual inoperable tumour, and in all of these patients VMA was raised before treatment. In one patient with a pelvic tumour VMA fell after treatment, but in the other 2 patients it remains raised in association with an inoperable ganglioneuroblastoma.

There were 32 children over the age of one year who died of their disease. Only 2 were referred directly to this hospital by their general practitioner, the rest being transferred from other hospitals with widespread metastatic disease. In 15 children, the possibility of neuroblastoma or other metastatic malignancy had not been considered in the differential diagnosis and at no time had VMA been measured, though in some instances the child had been in hospital for several weeks undergoing extensive investigations. The main symptoms of lethargy, weight loss, pallor, and generalized aches and pains often associated with a limp had been ascribed to such causes as osteomyelitis, myopathy, rheumatic fever, or juvenile rheumatoid arthritis. One child had been treated for 3 months for 'rheumatism' and in spite of the fact that VMA had been measured and was grossly abnormal on three occasions, the diagnosis of neuroblastoma was not considered until multiple metastatic lesions were noted on bone $x$-rays (Bond, 1974).

In the remaining 14 patients, a clinical diagnosis of neuroblastoma had been suspected because of gross periorbital bruising and proptosis, a thoracic or abdominal mass, an abnormal intravenous pyelogram, $x$-ray evidence of metastatic bone lesions or malignant cells in the bone marrow biopsy. In only 5 patients in this group was the VMA level measured during the initial investigations in order to confirm the suspected diagnosis.

The VMA level was persistently raised in 28 of the 32 patients over one year of age who died. In the 4 patients in who the VMA level was normal, the primary tumour was thoracic, retroperitoneal, adrenal, and pelvic, respectively. There were widespread metastases in all but 2 patients and in

TABLE IV

8 surviving children over age 1 year with neuroblastoma

\begin{tabular}{|c|c|c|c|c|c|}
\hline Case no. & Sex \& age (yr) & Stage & Site of tumour & Initial VMA (mg/24 h) & Treatment and survival \\
\hline \multicolumn{2}{|c|}{ Disease-free survivors } & & & & \\
\hline 1 & M 21 & III & Thoracic ganglioneuro- & Normal & Resection; alive $4 \mathrm{yr}$ \\
\hline 2 & M 3t & II & $\begin{array}{l}\text { Abdominal ganglioneuro- } \\
\text { blastoma }\end{array}$ & 13.9 (became normal) & Resection; radiotherapy; \\
\hline 3 & M $5 \frac{1}{2}$ & III & $\begin{array}{l}\text { Thoracic intraspinal ganglio- } \\
\text { neuroblastoma }\end{array}$ & Normal & $\begin{array}{l}\text { Resection; radiotherapy; } \\
\text { alive } 4 \mathrm{yr}\end{array}$ \\
\hline 4 & F $1 \frac{1}{2}$ & III & $\begin{array}{l}\text { Thoracic intraspinal } \\
\text { neuroblastoma }\end{array}$ & $4 \cdot 8$ (became normal) & $\begin{array}{l}\text { Resection, laminectomy; } \\
\text { radiotherapy; chemotherapy; } \\
\text { alive } 2 \text { yr }\end{array}$ \\
\hline 5 & F 1 19 & III & $\begin{array}{l}\text { Retroperitoneal intraspinal } \\
\text { neuroblastoma }\end{array}$ & 41 (became normal) & $\begin{array}{l}\text { Resection; radiotherapy; } \\
\text { chemotherapy; alive } 3 \text { yr }\end{array}$ \\
\hline \multicolumn{2}{|c|}{ Residual tumour } & & & & \\
\hline 6 & M 3 & III & $\begin{array}{l}\text { Inoperable pelvic neuro- } \\
\text { blastoma }\end{array}$ & 28 (became normal) & $\begin{array}{l}\text { Biopsy; radiotherapy; alive } \\
2 \frac{1}{2} \text { years }\end{array}$ \\
\hline 7 & M 9 & III & $\begin{array}{l}\text { Inoperable pelvic neuro- } \\
\text { blastoma }\end{array}$ & 279 (remained raised) & $\begin{array}{l}\text { Biopsy; radiotherapy; chemo- } \\
\text { therapy; alive } 2 \mathrm{yr}\end{array}$ \\
\hline 8 & F 4 & III & $\begin{array}{l}\text { Inoperable abdominal } \\
\text { ganglioneuroblastoma }\end{array}$ & 30 (remained raised) & $\begin{array}{l}\text { Biopsy; radiotherapy; } \\
\text { chemotherapy; alive } 4 \mathrm{yr}\end{array}$ \\
\hline
\end{tabular}


the absence of histology of the primary tumour, the raised VMA confirmed the suspected diagnosis of metastatic neuroblastoma. The raised VMA levels ranged from just above normal to $184 \mathrm{mg} / 24 \mathrm{~h}$, and the average levels in the nonsurvivors were no higher than in those patients who survived.

In only one patient who died was the histology other than that of malignant neuroblastoma. The patient had an apparently benign thoracoabdominal ganglioneuroma. This later extended through the intervertebral foramina to cause spinal cord compression. 2 years after partial resection of the primary tumour and a decompressive laminectomy, the patient developed widespread bone metastases. VMA had remained persistently raised throughout the course of the disease.

\section{Discussion}

Neuroblastoma is unique among the malignant embryonal tumours of childhood in its ability to produce abnormal urinary levels of metabolites which can easily be detected and should lead to early diagnosis. It is in this disease more than in any other childhood malignancy that the patient presents with widespread metastases in the absence of any clinically obvious primary tumour. There may be a variety of confusing and often apparently unrelated symptoms which may lead to the wrong initial diagnosis being made (Bond, 1972). While biopsy of the bone marrow, lymph nodes, or bone lesions may reveal malignant infiltration, the nature of the primary tumour may not always be definitely confirmed without evidence of abnormal catecholamine excretion, which is specific for neuroblastoma and does not occur in other malignant embryonal tumours.

The first report of a patient with increased urinary excretion of catecholamines in association with neuroblastoma appeared in 1957 (Mason et al.) and, in 1960, Voorhess and Gardner suggested that serial determinations might be of prognostic significance and of use in assessing response to therapy. However, the practical value of measuring abnormal catecholamines in patients with neuroblastoma, either as an early diagnostic test or as a method of monitoring response of the disease to treatment, has not always been appreciated. A retrospective study of 639 children with neuroblastoma seen in various centres in Britain between 1962 and 1967 (Kinnier Wilson and Draper, 1974) revealed that an initial VMA estimation was carried out in 109 patients, and that in only 33 of them were serial VMA levels recorded (Kinnier Wilson, 1974).

The introduction of the Labrosse spot test has provided a quick, simple screening test which can be performed on a few drops of urine. It is accurate, being positive in all patients with a raised $\vec{F}$ urinary VMA, and rarely if ever produces a false- $\stackrel{?}{?}$ positive result (Evans et al., 1971a). There is no need for previous dietary restrictions to be imposed on the child. The quantitative estimation of the $\frac{\sigma}{\sigma}$ 24-hour excretion of VMA is a more lengthy $\stackrel{\mathbb{\Omega}}{\varrho}$ investigation but provides extremely important के information when the progress of the disease and $\vec{A}$ response to treatment is being monitored (Liebner and Rosenthal, 1973). The return of the VMA to $\vec{\omega}$ normal levels after treatment is an important prognostic factor in predicting the likelihood of survival (Gitlow et al., 1973). It is also an important guide when assessing the need for further treatment. Long-term disease-free survival was also associated with the other known good prognostic factors such as age under one year at diagnosis, primary tumour in the thorax (Filler et al., $\stackrel{-}{\supset}$ 1972), and histological evidence of tumour differen- $\infty$ tiation. Metastases to bone continue to indicate a very poor prognosis and it is very rare for any patient with this pattern of disease to survive for more than 12 months.

While a better prognosis is associated with a $\vec{\varphi}$ benign ganglioneuroma or ganglioneuroblastoma, oै the diagnosis can be misleading when biopsy is not representative of the histological structure of the entire tumour (Dargeon, 1962), One patient in this series developed bone metastases from an apparently benign ganglioneuroma which had been associated with a persistently raised VMA level for the preceding 2 years. This suggests that there should be careful follow-up of the 3 other patients with residual inoperable tumours and raised VMA levels, even though 2 of them have survived for 4 years without further activation of their disease. In all the patients who died the VMA which had been raised at initial diagnosis remained raised throughout their illness.

It is difficult to predict with absolute certianty when a patient has been cured of neuroblastoma, and though a disease-free period of 2 years is usually taken to indicate that the disease has probably been eradicated, there have been instances of late relapse (Konrad, Singher, and Neerhout, 1973; Liebner and Rosenthal, 1973). It is therefore very important to continue to do serial VMA estimations on all patients throughout the follow-up period. In patients in whom the clinical picture is confusing but suggests the possibility of metastatic malignant disease, early estimation of VMA can avoid subjecting the child to a battery of complex and unnecessary investigations which are not needed to confirm the diagnosis of neuroblastoma. 
I thank Professor Barbara Clayton for helpful advice, the paediatricians and paediatric surgeons at The Hospital for Sick Children for permission to include details of their patients, and Mrs. S. Atherden for laboratory assistance.

\section{REFERENCES}

Bond, J. V. (1972). Unusual presenting symptoms in neuroblastoma. British Medical fournal, 2, 327.

Bond, J. V. (1974). Misdiagnosis in Still's disease. British Medical Fournal, 2, 56.

D'Angio, G. J., Evans, A. E., and Koop, C. E. (1971). Special pattern of widespread neuroblastoma with a favourable prognosis. Lancet, 1, 1046.

Dargeon, H. W. (1962). Neuroblastoma. Fournal of Pediatrics, 61, 456.

Evans, A. E., Blore, J., Hadley, R., and Tanindi, S. (1971a). The Labrosse spot test: a practical aid in the diagnosis and management of children with neuroblastoma. Pediatrics, 47, 913.

Evans, A. E., D'Angio, G. J., and Randolph, J. (1971b). A proposed staging for children with neuroblastoma. Cancer, 27, 374.

Filler, R. M., Traggis, D. G., Jaffe, N., and Vawter, G. F. (1972). Favourable outlook for children with mediastinal neuroblastoma. Fournal of Pediatric Surgery, 7, 136.

Gitlow, S. E., Bertani, L. M., Rausen, A., Gribetz, D., and Dziedzic, S. W. (1970). Diagnosis of neuroblastoma by qualitative and quantitative determination of catecholamine metabolites in urine. Cancer, 25, 1377.
Gitlow, S. E. Dziedzic, L. B., Strauss, L., Greenwood, S. M., and Dziedzic, S. W. (1973). Biochemical and histologic determinants in the prognosis of neuroblastoma. Cancer, 32, 898.

Kinnier Wilson, L. M. (1974). Catecholamine excretion levels in neuroblastoma. British Medical fournal, 4, 105.

Kinnier Wilson, L. M., and Draper, G. J. (1974). Neuroblastoma, its natural history and prognosis: a study of 487 cases. British Medical Fournal, 3, 301.

Konrad, P. N., Singher, L. J., and Neerhout, R. C. (1973). Late death from neuroblastoma. Fournal of Pediatrics, 82, 80.

Labrosse, E. H. (1968). Biochemical diagnosis of neuroblastoma. Use of a urine spot test. Proceedings of the American Association of Cancer Research, 8, 39.

Liebner, E. J., and Rosenthal, I. M. (1973). Serial catecholamines in the radiation management of children with neuroblastoma. Cancer, 32, 623.

Mason, G. A., Hart-Mercer, J., Millar, E. J., Strang, L. B., and Wynne, N. A. (1957). Adrenaline-secreting neuroblastoma in an infant. Lancet, 2, 322.

Pisano, J. J. Crout, J. R., and Abraham, D. (1962). Determination of 3-methoxy-4-hydroxymandelic acid in urine. Clinica Chimica Acta, 7, 285.

Ruthven, C. R. J. (1963). The Clinical Chemistry of Monoamines, p. 39. Ed. by H. Varley and A. H. Gowenlock, Elsevier, Amsterdam.

Voorhess, M. L., and Gardner, L. I. (1960). Catecholamine metabolism in neuroblastoma. Lancet, 2,651 .

Correspondence to Dr. Jane V. Bond, Institute of Child Health, Guilford Street, London WC1. 